\title{
A BIOÉTICA E O BIODIREITO: ASPECTOS E CONTROVÉRSIAS
}

\section{Günther Maluschke}

Doutor em Filosofia pela Universidade de Bonn. Livre-docente pela Universität Tübingen (Alemanha). Professor titular da Universidade de Fortaleza. maluschke@gmail.com

Sumário: Introdução. 1) Problemas epistemológicos e incertezas morais. 2) Relação entre Bioética e Biodireito. 3) Aborto e pesquisas com célulastronco embrionárias. 4) Direitos dos pacientes terminais.

Resumo: Nesta conferência ${ }^{1}$, analisam-se as relações entre a Bioética e o Biodireito assim como os desafios que as duas disciplinas enfrentam, tratando temas como aborto, pesquisas com células-tronco embrionárias, eutanásia, distanásia e suicídio assistido. Defendem-se uma Ética inventiva e um Direito criativo, ambos dispostos a aprender pelos seus erros e com sensibilidade para os casos difíceis no início e no fim da vida humana.

Palavras-chave: Bioética. Biodireito. Ética Inventiva. Direito Criativo.

\section{INTRODUÇÃO}

Nesta conferência, vou defender algumas idéias que gostaria de apresentar já no início em forma de três teses.

A primeira tese é a seguinte: são, sobretudo, inquietadoras incertezas morais que são a principal razão pela qual se ocasionou a formação das duas disciplinas relativamente novas da Bioética e do Biodireito.

A segunda tese: As incertezas normativas nos acompanharão futuramente, $\mathrm{e}$ quem espera da Bioética e do Biodireito soluções definitivas ficará decepcionado não só pela minha conferência, mas também no futuro não encontrará tais soluções.

A terceira tese: Aqueles que pretendem apresentar soluções definitivas e imutáveis para os problemas da Bioética e do Biodireito - isto é, para os problemas morais e jurídicos que são os objetivos dessas disciplinas - enganam o público, pois tais soluções são além do alcance da inteligência humana.

${ }^{01}$ Conferência proferida na abertura do V Encontro de Iniciação à Pesquisa, em 27/maio/2009, do curso de Direito da FA7. 
Sintetizando essas três teses, devo dizer que meu objetivo é bastante modesto: pretendo lhes apresentar propostas provisórias de soluções que um dia poderão ser superadas por outras propostas melhores. Inicialmente tenho a intenção de analisar as controvérsias e as dificuldades de alcançar consensos no contexto de nossa temática. Na verdade, prevalecem muitas dúvidas, e há poucas certezas. Prevalecem os dissensos.

Em primeiro lugar, devemos entender o que é Bioética e o que é Biodireito. Uma primeira resposta pode ser a constatação de que são subdisciplinas de outras disciplinas, isto é, disciplinas derivadas de outras disciplinas: a Bioética é uma subdisciplina da Ética; o Biodireito é uma subdisciplina do Direito. Ambas as palavras começam com o antepositivo bio do grego bios, o que significa "vida". São determinados grandes problemas da vida e suas implicações morais que são o objeto tanto da Bioética quanto do Biodireito.

A Bioética é o estudo dos problemas morais despertados pelas pesquisas científicas em biologia e medicina assim como especialmente no campo da genética. As questões principais da Bioética são a utilização de seres vivos e até de homens em experimentos, a legitimidade moral do aborto, da pesquisa com células-tronco embrionárias, da eutanásia, da distanásia , isto é, da obstinação terapêutica que, custe que custar, pretende prorrogar a vida de um paciente terminal, do suicídio, do suicídio assistido por médicos etc. Como todos esses problemas morais são também problemas jurídicos, os Estados têm a obrigação de criar normas jurídicas para impedir eventuais abusos das novas possibilidades de intervenção médicas que a engenharia genética e outras biotecnologias sofisticadas oferecem.

\section{Problemas epistemológicos e incertezas Morais}

Acabei de dizer que a Bioética é uma subdisciplina da Ética. Por isso devo, em poucas palavras, explicar como eu vejo o status epistemológico da Ética. Compartilho com o filósofo Karl Popper a opinião de que a Ética não é uma ciência ${ }^{2}$. Normas são feitas pelo homem, os seres humanos introduziram normas no mundo. Tanto as normas éticas quanto as normas jurídicas são invenções humanas. Não há nem ética natural nem direito natural. Concordo plenamente com a afirmação de Popper: "A natureza consiste de factos e de regularidades, não sendo em si mesma nem moral nem imoral. Nós é que impomos nossos padrões à natureza, desse modo introduzindo a moral no mundo natural."’3

2 Cf. Popper, K.R., A Sociedade Aberta e Seus Inimigos, Belo Horizonte/São Paulo: Editora Itatiaia Limitada, t. II, p.246.

3 Ibid., t. I, p.75 
Por que a Ética não é uma ciência? A resposta é simples. Ciências descrevem e explicam os fenômenos e regularidades do mundo; normas éticas - repito - não são fenômenos ou regularidades do mundo. Ciências não criam normas, não inventam normas. Somos nós, homens vulneráveis e necessitando de proteção, que introduzimos concepções éticas no mundo natural. Éticas são criações culturais. Agora falei de éticas, de uma pluralidade de éticas. Isto, de fato, é totalmente correto, pois em nosso mundo não existe uma única Ética como existe uma única Matemática, uma única Física, Química, Biologia, Engenharia Genética. Matemática, Física, Química, Biologia podem ser estudadas em qualquer país civilizado, e novas descobertas nessas disciplinas são válidas para o mundo inteiro. Quanto à Ética, isso não é o caso. E também dentro da mesma cultura há opiniões morais heterogêneas, influenciadas por diferentes religiões e ideologias. Esta heterogeneidade das opiniões confirma o fato de que encontramonos num campo de grandes incertezas. Teorias científicas são sustentadas por controles empíricos. Podemos deplorar que uma questão de interesse vital como a diferença entre o bem e o mal não pode ter uma comparável pretensão à objetividade. Isto, contudo, é um fato.

Não sabendo o que devemos fazer, devemos nos contentar em decidir o que queremos fazer. Mas o nosso querer também não é determinado por regras universalmente válidas. Nosso livre-arbítrio, nossa capacidade de escolher em função de nossa vontade, implica o perigo de decisões anti-sociais. E é esse perigo que, desde tempos imemoriais, motivou os homens a criar éticas e sistemas jurídicos. Esses sistemas normativos devem continuamente ser adaptados às novas situações e aos novos desafios. A criação das disciplinas da Bioética e do Biodireito é, de fato, uma resposta a novas situações e novos desafios.

Foram, sobretudo, as invenções de máquinas medicinais eficientes - máquina de circulação extracorpórea, coração artificial, incubadora, aparelhos de diagnósticos altamente sofisticados - e, especialmente, os progressos rápidos da biotecnologia e da engenharia genética que sobrecarregaram os profissionais da saúde com novas responsabilidades e mostraram que a ética médica tradicional tinha perdido sua força de orientação. A dinâmica do progresso científico-técnico gerou novas incertezas morais de grande peso, pois, com o aumento das competências técnicas, o homem está a ponto de se tornar objeto de manipulação e alteração na sua natureza fisiológica e até na profundeza de sua constituição genética.

As velhas evidências morais - que, em parte talvez tenham sido pseudoevidências - falharam em face dos desafios surgidos em decorrência da abundância das possibilidades técnicas que, incluindo projetos de autocriação humana, abrangem também riscos de autodestruição. Aqui só menciono os projetos moralmente problemáticos de clonagem humana.

O impacto das biotecnologias de ponta sobre o clima nos hospitais e sobre a relação entre médicos e pacientes é muito forte. Com as novas capacidades 
tecnológicas surgiram possibilidades anteriormente inconcebíveis de salvar vidas, mas estão também à disposição as técnicas de prorrogar a vida e os sofrimentos de pacientes terminais, mantendo-os vivos em condições terríveis. A questão moral que se faz agora é: De que maneira devem ser utilizadas as possibilidades extraordinárias das tecnologias de ponta na medicina? Todos esses problemas são um campo de grandes controvérsias.

\section{RelaÇão entre Bioética e Biodireito}

O próximo tema sobre o qual devo versar agora é a relação entre Bioética e Biodireito. Quem quer se dedicar a esse tema, poderia, em primeiro lugar, tentar se informar sobre o significado desses dois termos por meio de dicionários. Neste caso, porém, tal tentativa poderia induzi-lo em confusões, pelo menos se ele tiver a idéia de consultar os mesmos dicionários jurídicos como eu para se informar sobre o conceito "biodireito". Quem abre um desses dicionários depara-se com a seguinte explicação: "É a positivação ou tentativa de positivação das normas bioéticas; ou seja, a positivação de permissões de comportamentos médico-científicos e das sanções pelo descumprimento destas normas." ${ }^{4}$ Em outro dicionário, biodireito é definido como "disciplina oriunda da interdisciplinaridade entre a bioética e o direito." "As duas definições nâo se harmonizam uma com a outra. De acordo com a primeira, o sujeito do Biodireito seria o legislador, no Brasil, o congresso, que cria normas jurídicas, positivando, no caso específico, "normas bioéticas". Na segunda definição, Biodireito é uma disciplina jurídica que, para realizar seu objetivo, deve colaborar com outra disciplina, a Bioética. Enquanto a primeira definição apresenta o Biodireito como prática legisladora, a segunda a determina como estudo teórico com fins jurídico-práticos. Ambas as definições são reducionistas; portanto, não estão à altura de conceituar a pluridimensionalidade daquilo que se pode designar de Biodireito, e também não correspondem à pluridimensionalidade da Bioética. O reducionismo, porém, não é a única falha dessas definições; além disso, são impróprias por causa da ênfase exagerada da relação harmoniosa entre Bioética e Biodireito. Essa relação, de fato, não é tão harmoniosa.

A primeira definição acentua inapropriadamente o entrelaçamento entre positivação e normas bioéticas, como se as normas biojurídicas fossem as simples positivações das normas propostas pelos especialistas da Bioética, como se não houvesse casos de conflito entre as concepções dos bioeticistas e o legisladores.

\footnotetext{
${ }^{04}$ De Plácido e Silva, Vocabulário Jurídico. Atualizadores: Slaibi Filho e Gláucia Carvalho, $27^{\mathrm{a}}$ ed., Rio de Janeiro: Editora Forense 2008, p. 223.

${ }^{05}$ Acquaviva, Marcus Cláudio, Dicionário Jurídico Acquaviva: Editora Rideel, p. 141.
} 
A segunda exagera a interdisciplinaridade, como se entre bioeticistas e juristas prevalecesse o consenso com respeito, por exemplo, a temas como aborto, pesquisas com células-tronco embrionárias, eutanásia, suicídio assistido etc.

Eu já assinalei anteriormente que foram as incertezas morais que ocasionaram o surgimento da Bioética. A novidade da Bioética em relação à Ética tradicional consiste no alargamento das perspectivas para estratégias de solução de problemas extremamente complexos na área biomédica. Surgiu o medo de que o homem, na sua natureza humana, se torne mero objeto de disposição das tecnologias de ponta na medicina. As incertezas morais são, portanto, o reverso da medalha do espantoso progresso biotecnológico.

Com o aumento das capacidades tecnológicas alargam-se também as proporções das responsabilidades dos profissionais de saúde. Médicos e médicas, enfermeiros e enfermeiras assim como assistentes técnicos enfrentam tanto conflitos de consciência individual quanto perplexidades perante zonas de incerteza jurídicas. Sobretudo em casos difíceis - no início e no fim da vida - nem os padrões éticos tradicionais nem o direito vigente oferecem orientações certas para a prática profissional. Tanto os eticistas quanto os juristas devem explorar novos horizontes.

$\mathrm{Na}$ tentativa de elaborar orientações normativas que estejam à altura dos desafios atuais, os especialistas de Ética, em geral filósofos e teólogos, e os juristas podem convergir ou divergir. De fato, há grandes divergências entre os eticistas. É verdade que os juristas têm na Constituição de seus países um guia orientador em comum, mas também entre eles existem discordâncias no âmbito dos novos problemas normativos. De modo geral, pode-se dizer que se formaram duas tendências na área tanto da Bioética quanto do Biodireito: concepções conservadoras, por um lado, e concepções crítico-liberais, por outro lado. Há, com certeza, grande concordância entre os especialistas da Ética e os juristas que defendem posições conservadoras e aqueles que apóiam posições liberais. Podese constatar, porém, que também entre os teóricos ideologicamente próximos, às vezes, surgem divergências; na interpretação dos princípios normativos não existem sempre concordâncias entre especialistas de Ética e juristas conservadores ou entre eticistas e juristas liberais, porque tanto os métodos quanto as tradições do pensamento ético e da teoria jurídica são diferentes.

No concernente à posição conservadora, na Europa e no Brasil são, sobretudo, as concepções dogmáticas do catolicismo que se impuseram. Em comparação a isto, as idéias crítico-liberais caracterizam-se por certo pluralismo. Nos terrenos da Bioética e do Biodireito confrontam-se idéias heterogêneas. Na Bioética, os debates continuam, e na Filosofia Moral, que já há muito tempo se emancipou da Teologia, prevalece cada vez mais a conviç̧ão de que certezas absolutas de orientação normativa são inacessíveis, ou se apresentam como expressão dogmática de uma fé religiosa que não tem o apoio de argumentos universalmente aceitáveis. 
Como o sistema jurídico não pode esperar o fim do debate bioético, que, com certeza, jamais terminará, os legisladores não podem deixar de diminuir as incertezas jurídicas por propostas de leis positivas. Desde que são oficialmente decretadas, a validade de tais leis está fora de dúvida. Não obstante, a crítica acadêmica de leis vigentes sempre é possível. Leis conservadoras ou uma jurisprudência demasiado tradicionalista podem ser objetos de críticas por parte dos pesquisadores na área da biologia e da genética, o que fizeram, no Brasil, pesquisadores que planejaram experimentar com células-tronco embrionárias; mas uma jurisprudência conservadora pode também ser criticada por parte daqueles eticistas ou juristas que defendem concepções mais liberais. Por outro lado, também as leis progressistas, que abrem amplo espaço de pesquisa na área da engenharia genética, não são isentas da crítica dos pesquisadores e bioeticistas conservadores. Ambas as profissões, a dos especialistas de Ética e a dos juristas, enfrentam a tarefa de tentar tomar as decisões racionalmente mais adequadas possíveis em condições em que certezas absolutas são fora de nosso alcance. Precisamos de um pensamento ético inventivo e de uma jurisprudência criativa que acompanhem o progresso científico e criem orientações normativas que não mais procuram a meta ilusória de certeza absoluta, mas se contentam com normas suscetíveis de reavaliação e revisão.

\section{Aborto e pesquisas COM CÉlulas-TRONCO EMbrionáRIAS}

Abordarei agora algumas controvérsias no contexto da Bioética e do Biodireito. Foi amplamente noticiado que no dia 29 de maio de 2008 o Supremo Tribunal Federal aprovou, sem restrições, a continuidade das pesquisas com células-tronco embrionárias no país. Sabemos que cinco votos fizeram ressalvas e que a maioria com seis votos venceu. Percebe-se que entre os ministros houve dissensos. A Ação de Inconstitucionalidade da Lei de Biossegurânça foi rejeitada por apenas seis votos contra cinco. A Conferência Nacional dos Bispos do Brasil (CNBB) lamentou a decisão do Supremo Tribunal de liberar as pesquisas. Na Bioética, a Igreja Católica defende a posição de que já o zigoto é uma pessoa humana, e por isso considera a utilização de células-tronco embrionárias como homicídio. Neste caso, o conflito entre a posição da Igreja Católica e a jurisprudência brasileira é evidente.

Quanto ao aborto, também há um conflito insuperável entre a posição rígida da Igreja Católica e a nossa jurisprudência. Neste ano, em março, o Arcebispo de Recife e Olinda, Dom José Cardoso Sobrinho declarou publicamente a excomunhão dos médicos que interromperam a gravidez de uma menina de nove anos, vítima de estupro de seu padrasto. Muitos brasileiros se solidarizaram com os médicos e criticaram o Arcebispo. Recebi um apelo para enviar uma mensagem 
de solidariedade à direção do Centro Integrado de Saúde Amaury de Medeiros e à equipe de atenção de saúde que, como escreveram, "têm sido violentamente atacados por parte da Igreja Católica." Respondi positivamente, mas não sei se gostaram de minha resposta. Vou citar só algumas passagens.

Depois de ter manifestado minha solidariedade para com aqueles médicos, escrevi o seguinte: "Tenho, portanto, dificuldades de entender por que uma instituição e pessoas que, no cumprimento de seus deveres, não tiveram problemas de consciência - ou resolveram esses problemas com argumentos válidos - fazem apelos de solidariedade e pedidos de apoio. Por que precisam da solidariedade de outras pessoas? ... Não critico nem defendo o arcebispo. Constato a obstinação dogmática e as convicções retrógradas dele, mas acredito que ele também agiu em concordância com sua consciência e suas convicções. Ele é simplesmente o servo obediente ... de sua Igreja. E de acordo com o Direito Canônico, o aborto de fato é caso de excomunhão latae sententiae, isto é, automática. O que Dom José Cardoso Sobrinho fez? Informou o público brasileiro sobre este dogma. Não foi ele que excomungou os envolvidos... Penso que manifestações de indignação direcionadas contra o arcebispo são inadequadas. $\mathrm{O}$ verdadeiro problema é a respectiva doutrina da Igreja Católica. Esta deve ser objeto da crítica. Os médicos sabem que não se pode desenvolver um tratamento médico adequado a partir de um diagnóstico errado. As pessoas, os homens da Igreja não são o verdadeiro problema ... Dificilmente a Igreja Católica pode separar-se das regras medievais do Direito Canônico. O conflito com concepções de moralidade profana e o direito positivo dos Estados modernos permanecerá. Os médicos devem se acostumar a serem alvos de críticas desta igreja e treinar a arte de ficarem imperturbáveis."

Até aqui o recorte de minha declaração ao Centro Integrado de Saúde Amaury de Medeiros. O arcebispo Dom José Cardoso Sobrinho é um defensor do Direito Natural. Considera o Direito Canônico baseado no Direito Divino, e consequentemente afirma que, em caso de conflito entre Direito Divino e direito positivo, este último não é válido. As leis brasileiras que permitem o aborto de uma gravidez decorrente de estupro e também quando a mãe corre risco de vida para o arcebispo não são válidas. Os conflitos entre um Direito Natural pré-moderno e os sistemas do direito positivo são insuperáveis, e tais conflitos hoje se manifestam de maneira particularmente intensiva nos terrenos da Bioética e do Biodireito.

\section{DiREITOS DOS PACIENTES TERMINAIS}

Na Bioéica e no Biodireito, na cultura ocidental, estabeleceu-se o consenso segundo o qual a dignidade do moribundo deve ser respeitada. Esse consenso parece ser bastante estável quando se fala da dignidade do moribundo no sentido abstrato. O consenso se torna complicado, no entanto, quando surgem problemas 
muito concretos na fase final da vida, por exemplo: um paciente sofre de dores insuportáveis e quer morrer o mais rapidamente possível; outro não quer mais comer e beber para acelerar o processo de morrer e se recusa de aceitar alimentação forçada; outra pessoa na fase final da vida quer se suicidar e pede do médico orientação e auxílio para esse ato. Será que, em tais casos, o princípio de autonomia é válido? Será que os médicos devem respeitar a autonomia do paciente e agir de acordo com a vontade dele? Obviamente não se pode deduzir do princípio de dignidade da pessoa humana uma orientação concreta para resolver problemas desta natureza. Tais casos provocam muita discussão, e se torna evidente que o consenso abstrato atinente ao respeito da dignidade do paciente terminal é um consenso fraco. Quando se pergunta: "Respeitar a dignidade do moribundo significa respeitar sua vontade"? a resposta geralmente é ambígua.

Genival Veloso de França, por exemplo, defende a tese de que "a morte, em qualquer circunstância, é sempre o mal maior". ${ }^{6}$ Será que ele defenderia também a idéia de que a vida é sempre, em qualquer circunstância, o bem maior? A afirmação de França é extremamente problemática, pois para um moribundo a morte pode ser a única salvação de dores insuportáveis e de sofrimentos psíquicos profundos. Por isso, também a tese complementar "a vida é sempre, em qualquer circunstância, o bem maior" é inaceitável. Há, infelizmente, circunstâncias nas quais a vida perde seu valor.

Geralmente, França segue piamente o ensinamento ético da Igreja Católica. Na mesma página, França cita uma passagem da Declaração sobre a Eutanásia (1990) da Igreja Católica:

Na iminência de uma morte inevitável é lícito de forma consciente formar a decisão de renunciar ao tratamento que daria somente um prolongamento precário à vida, sem, contudo interromper os cuidados normais devidos ao doente em casos semelhantes. ${ }^{7}$

Conforme fica claro pelo contexto, "cuidados normais" significam nada mais do que alívios de sofrimento. A vontade do moribundo não está no centro do discurso de França.

O raciocínio apresentado é inconsistente. Obviamente, a Igreja Católica, cujas idéias ético-jurídicas geralmente são o guia para França, não pode declarar que a morte, em qualquer situação, é o mal maior. Assumamos que o catolicismo não abandona suas tradições e permanece conseqüente nas suas esperanças escatológicas. Então, o mal maior é uma forma específica de vida, isto é, a vida dos

${ }_{6}$ França, G. V. de, Medicina Legal, Rio de Janeiro, Editora Guanabara Koogan S. A., $5^{\text {a }}$ ed., 1998, p.303.

7 Ibid. 
pecadores no inferno, uma vida eterna com dores fortíssimos e sem fim. Para esta fé religiosa a vida terrestre também não é o bem maior; o bem maior é a vida dos bem-aventurados no paraíso. Por conseguinte, para essas pessoas felizes a morte não era o mal maior, só era uma passagem para outra vida. Há três anos, li numa revista alemã a seguinte notícia: $\mathrm{Na}$ Áustria, um abade recebeu uma carta de um bispo amigo em que este o informou que estava sofrendo de um câncer incurável e já se preparando para a morte. Imediatamente o abade respondeu: "Parabéns. Em breve o Senhor estará no Paraíso. Como eu gostaria de acompanhar o Senhor."

A alta valorização da vida terrestre é, de fato, a conseqüência de uma concepção moderna e não religiosa de uma vida temporalmente limitada; nesta perspectiva, a morte eventualmente possa ser considerada como "mal maior", porque não há mais nenhuma esperança de uma outra vida após a morte. No entanto, nem mesmo nesta ótica a obstinação terapêutica poderia ser justificada por meio de bons argumentos, mas tal tendência seria um pouco mais plausível do que no contexto de convicções religiosas. No que concerne à rejeição da distanásia, França assume o respectivo ensinamento da Igreja Católica, sem perceber que, para ser conseqüente, deveria ter abandonado a idéia sobre a morte como mal maior.

A palavra "distanásia", antônimo de "eutanásia", mas muito menos conhecida do que esta, é um neologismo de origem grega e significa "morte difícil, lenta, penosa e com muito sofrimento". Por extensão semântica, a palavra distanásia usa-se também para indicar o tratamento inútil, a obstinação terapêutica, isto é, a atitude de médicos que, visando a salvar a vida do paciente terminal, custe que custar, submete-o a grande sofrimento. Deste modo, prolonga-se muito mais o processo de morrer do que a vida propriamente dita.

Nas áreas da Bioética e do Biodireito, a "eutanásia" é muito mais discutida do que a distanásia, mas com certeza a última está sendo muito mais praticada nas instituições de saúde, notadamente nas unidades de terapia intensiva. As práticas distanásicas até estão sendo ocultadas ao público, como se fossem práticas de tabu, pois nas manchetes de noticiários e jornais quase nunca informações sobre isso são divulgadas.

Em maio de 1999, porém, o Dr. John Hansen publicou no Washington Post um artigo intitulado "Escolhendo morte ou mamba em UTI", com o seguinte teor: Três missionários foram aprisionados por uma tribo de canibais, cujo chefe lhes ofereceu escolherem entre morte ou mamba - mamba é uma serpente africana peçonhenta, cuja picada inflige grande sofrimento antes da morte certa ou quase certa. Dois deles, sem saber do que se tratava, escolheram mamba e aprenderam da maneira mais cruel que mamba significava uma longa e torturante agonia, para só então morrer. Diante disso, o terceiro missionário rogou pela morte, ao que o chefe da tribo respondeu-lhe: "Morte você terá, mas primeiro um pouquinho de mamba."

A tese do Dr. Hansen é de que, como os missionários que não sabiam o que era mamba, por sua vez o público em geral desconhece as práticas de tratamento 
inútil e de obstinação terapêutica nas unidades de terapia intensiva de hoje. Há ainda muitas equipes médicas que aceitam a batalha contra a morte por meio da poderosa tecnologia médica até o último momento, porque, em vez de se entender a morte como um acontecimento normal e inevitável, ela é, sobretudo, encarada como falha da medicina, como se fosse o último desafio a ser superado. Afinal de contas, porém, a morte sempre vencerá.

Será que o suicídio, em qualquer circunstância, é condenável? Será que um prisioneiro num campo de concentração, todos os dias humilhado e mal tratado, sem perspectiva de um dia levar uma vida em liberdade, não deve suicidar-se? Quem conhece as normas universalmente válidas que em caso tão difícil devem ser respeitadas?

Há mais ou menos trinta anos, um filósofo da Universidade de Viena (Áustria) ficou internado num hospital com uma doença incurável. As dores pioraram e a vida se transformou em pesadelo. Um dia ele pediu a um colega que o tinha visitado o favor de transmitir aos outros colegas da Universidade a seguinte informação: quem quisesse visita-lo deveria fazer isto na semana seguinte. Após esta semana, ele se defenestrou. Cometeu um suicídio bem premeditado.

Quem tem o direito de condenar este ato? Quem acredita em Deus, a ele deve deixar a sentença. Quem não acredita em Deus deve também se abster de qualquer julgamento.

Hoje, na Holanda e na Suíça, o suicídio assistido em instituições especiais é legalizado. É bem possível que o filósofo vienense teria escolhido tal prática de suicídio assistido, se naquela época esta possibilidade tivesse existido.

Esta consideração não deveria ser compreendida como proclamação para a despenalização do suicídio assistido ou até para sua institucionalização. As vantagens e desvantagens e os possíveis perigos devem ser muito bem ponderados, e a formação de uma opinião apoiada por bons argumentos deve ser difícil. Talvez, porém, os veredictos tradicionais não se afirmem como bons argumentos, mas somente como dogmas. Não se pode excluir a possibilidade de que em futuras épocas outros dogmas prevalecerão.

Uma das teses principais de minha conferência é que não devemos sobrestimar nossa faculdade de estabelecer normas éticas e jurídicas universal e absolutamente válidas, e na aplicação de nossas normas não podemos esquecer de que não somos isentos de erros. Por isso, devemos ter cautela de princípios pretensamente absolutos e de sua aplicação.

Uma das mais repugnantes aplicações de um princípio absoluto, princípio da sacralidade da vida humana, pela jurisprudência foi realizada em 2007 na Alemanha ${ }^{8}$. Depois de um exame falho das vias respiratórias (erro médico), uma

${ }_{8}$ Caso relatado pela revista alemã Der Spiegel, n. 42, de 15 de outubro de 2007. 
menina de quatro anos caiu em coma vígil. Perdeu a capacidade de falar, não reconheceu seus pais, não se comunicava com ninguém. Havia sinais de vida, sim, sinais extremamente fortes: espasmos e gritos de dor que acompanharam os pesadelos da mãe por muito tempo. Os sedativos falharam. A criança foi submetida a tratamentos inúteis em vários hospitais especializados, inclusive a cirurgias. Tudo sem êxito. Quando os pais perceberam que não havia mais melhoria possível, decidiram que os tratamentos e as medidas de prorrogação da vida de sua filha não deveriam continuar. O chefe do setor pediátrico no qual ela estava internada fez intervir as autoridades estatais. Um tribunal desapossou aos pais, parcialmente, o poder pátrio, interditando-os de levar a criança para casa. Ela ficou no hospital, e as "torturas" e gritos de dor continuavam. Finalmente, depois de dez meses de luta, o Tribunal Estadual Superior de Hamm (Westfália) decidiu em favor da demanda dos pais. No dia 4 de julho de 2007, os pais levaram a filha para casa, onde o médico da família devia acompanhar a fase terminal da criança. O litígio ainda não terminou. No dia 7 de julho, os pais receberam, pelo fax, a notícia de que o Supremo Tribunal da Alemanha, de novo, tinha-lhes desapossado o poder pátrio. Tarde demais: a criança já tinha falecido.

As cartas de leitores da revista, publicadas na edição de 29 de outubro de 2007, foram unânimes na manifestação de horror sobre este rigorismo da jurisprudência (exceto o acórdão do Tribunal Estadual Superior de Hamm). "Quem nos protege de tais juízos ?", perguntou um dos leitores.

Por que, diante deste caso trágico, aos juristas do Supremo Tribunal faltou aquele tipo de sensibilidade que os leitores da revista manifestaram? Penso que é a ilusória certeza de dispor de certezas normativas irrefutáveis que induz a esta forma de endurecimento. Um pensamento ético inventivo e uma jurisprudência criativa, ambos dispostos a aprender pelos seus erros, poderiam desenvolver a sensibilidade desejável para casos difíceis na Bioética e no Biodireito.

\section{REFERÊNCIAS}

Acquaviva, Marcus Cláudio. Dicionário Jurídico Acquaviva: Editora Rideel.

De Plácido e Silva. Vocabulário Jurídico. Atualizadores: Slaibi Filho e Gláucia Carvalho, 27. ed., Rio de Janeiro: Forense, 2008.

França, G.V. de. Medicina Legal. 5. ed. Rio de Janeiro: Guanabara Koogan, 1998. Popper, K.R. A Sociedade Aberta e Seus Inimigos. Belo Horizonte/São Paulo: Itatiaia, 1987. 


\section{BIOETHICS AND BIOJURISPRUDENCE:} ASPECTS AND CONTROVERSY

Abstract: In this conference the relationship between Bioethics and Biojurisprudence is analyzed as well as the challenges that the two disciplines face dealing with themes such as abortion, embryonic stem cell research, euthanasis, disthanasis, and assisted suicide. We defend inventive ethical thought and a creative jurisprudence, with openness in order to learn with their mistakes and with sensibility for the hard cases in the beginning and the end of human life.

Keywords: Bioethics. Biojurisprudence. Inventive ethical thought. Creative jurisprudence. 